\title{
Effects of Steroid Hormones on Human Polymorphonuclear Leukocyte Lysosomes
}

\author{
Robert H. Perseluin and Leighton C. Ku \\ From the Rheumatology Division, Department of Medicine, University of Texas \\ Health Science Center, San Antonio, Texas 78284
}

\begin{abstract}
A B S T R A C T Lysosomal membrane stabilization has been proposed as a mechanism for the anti-inflammatory action of corticosteroid hormones. This hypothesis was based on studies with liver organelles. We studied the action of steroids on intact lysosomes isolated from human peripheral blood polymorphonuclear (PMN) leukocytes. Both androstenedione and progesterone, $10^{-3}-10^{-5}$ $M$, caused leakage of acid hydrolase markers from these organelles, thus resembling their effects on liver lysosomes. But none of the anti-inflammatory steroids tested protected organelle membranes from either detergent lysis (Triton $\mathrm{X}-100)$ or heat incubation $\left(37^{\circ} \mathrm{C}\right.$, $90 \mathrm{~min}$ ). Hydrocortisone ( $\mathrm{HC}$ ), $\mathrm{HC}$ sodium succinate, $\mathrm{HC}$ acetate, $\mathrm{HC}$ hemisuccinate, prednisone, and dexamethasone were without detectable stabilizing activity at concentrations of $10^{-3}-5 \times 10^{-8} \mathrm{M}$. Release of the lysosomal marker, $\beta$-glucuronidase, was not retarded by any of the compounds studied. In addition, PMN leukocyte lysosomes isolated from human volunteers receiving prednisolone were not more stable than control organelles, nor did serum from steroid-treated humans protect intact lysosomes from detergent lysis.

Variations in cholesterol and phospholipid contents of liver and PMN leukocyte lysosome membranes could possibly account for the different reactivity to corticosteroids observed. We believe that the anti-inflammatory activity of adrenal corticosteroids can best be explained by their inhibitory effects on cellular metabolism rather than by their direct interaction with lysosomal membranes.
\end{abstract}

\section{INTRODUCTION}

The anti-inflammatory action of adrenal corticosteroid hormones is believed to be mediated in part by their

This work was presented in part at the annual meeting of the American Rheumatism Association, June 1973, Los Angeles, Calif.

Received for publication 13 March 1974 and in revised form 5 June 1974. effects on lysosomal membranes. Early studies by de Duve, Wattiaux, and Wibo (1) and by Weissmann and Thomas (2) showed that hydrocortisone retarded the release of acid hydrolases from isolated lysosomes. Since the contents of these subcellular organelles can induce inflammation, inhibition of their release would modify and diminish the inflammatory process (3). These observations, however, were based on studies with liver lysosomes, subcellular organelles not usually involved with extrahepatic inflammation. Recent studies using phagocytic cells and bactericidal systems have failed to document stabilization by hydrocortisone of the lysosomes in these cells (4-6). Although Wright and Malawista (4) found less extracellular release of granular enzymes in $5 \times 10^{-4} \mathrm{M}$ cortisol, neither altered degranulation nor impaired intracellular digestion by $1 \mathbf{y -}$ sosomal hydrolases was detected by Mandell, Rubin, and Hook (5) or by Wiener, Marmary, and Curelaru (6). And no effects were observed by these authors using hydrocortisone in the usual physiologic and pharmacologic concentrations. Since the polymorphonuclear $(\mathrm{PMN})^{1}$ leukocyte is the dominant cell in acute inflammatory reactions-reactions that can be suppressed by corticosteroids-we have studied the effect of adrenocortical hormones on lysosomes isolated from these cells.

\section{METHODS}

Intact leukocyte lysosomes were isolated from normal human venous blood PMN leukocytes by the method of Chodirker, Bock, and Vaughan (7). Briefly, after hypotonic lysis of red cells in $0.2 \%$ saline and washing in $0.34 \mathrm{M}$ sucrose, leukocytes (75-90\% PMN) were disrupted by rapid pipetting in $0.2 \mathrm{M}$ sucrose containing aqueous heparin, $50 \mathrm{U} / \mathrm{ml}$. Intact large granules composed mainly of lysosomes were isolated by differential centrifugation (the organelles sedimenting between $800 \mathrm{~g}$ for $15 \mathrm{~min}$ and $25,000 \mathrm{~g}$ for $10 \mathrm{~min}$ ), washed, and suspended in $0.3 \mathrm{M}$ sucrose containing heparin so that the absorbance $520 \mathrm{~nm}$ of the suspension was 0.6-0.8. Approximately $30 \mathrm{ml}$ of a uni-

1 Abbreviations used in this paper: DMSO, dimethyl sulfoxide; PMN, polymorphonuclear. 
TABLE I

Effect of Incubation at $37^{\circ} \mathrm{C}$ for 90 min on Release of Enzymes from Human PMN Leukocyte Lysosomes*

\begin{tabular}{|c|c|c|c|c|}
\hline \multirow[b]{2}{*}{ Lysosomal fraction assayed } & \multicolumn{2}{|c|}{$\beta$-Glucuronidase $\ddagger$} & \multicolumn{2}{|c|}{ Acid phosphatase } \\
\hline & $A_{s b 0 \mathrm{~nm}}$ & $\begin{array}{l}\text { Percent } \\
\text { of total }\end{array}$ & $A_{420 \mathrm{~nm}}$ & $\begin{array}{l}\text { Percent } \\
\text { of total }\end{array}$ \\
\hline A. Activity in supernate before incubation & 0.076 & $15 \pm 1.1$ & 0.223 & $28 \pm 1.3$ \\
\hline B. Activity in supernate after $37^{\circ} \mathrm{C}$ incubation & 0.172 & $35 \pm 2.7$ & 0.379 & $47 \pm 3.1$ \\
\hline C. Activity released by incubation $(B-A)$ & 0.096 & $20 \pm 2.9$ & 0.156 & $19 \pm 3.6$ \\
\hline D. Activity recovered in pellet after incubation $\|$ & 0.321 & $65 \pm 4.3$ & 0.427 & $53 \pm 6.7$ \\
\hline E. Total enzyme content $(B+D)$ & 0.493 & $100 \pm 6.3$ & 0.806 & $100 \pm 8.9$ \\
\hline
\end{tabular}

* Intact granulocyte lysosomes were stressed by $37^{\circ} \mathrm{C}$ incubation and enzyme activities assayed in clear supernates. See text for details.

$\ddagger$ Presented are means \pm 1 SEM of 16 experiments, each with three to six replicates. All values have been corrected for substrate blanks.

$\S$ Presented are means $\pm 1 \mathrm{SEM}$ of four experiments, each with four to six replicates. All values have been corrected for substrate blanks.

$\|$ After $37^{\circ} \mathrm{C}-90 \mathrm{~min}$ incubation and centrifugation at $25,000 \mathrm{~g}$-10 min, the pelleted intact organelles were resuspended to original volume, disrupted by freezing and thawing seven times, and the liberated enzyme activities assayed in the clear supernates after centrifugation to remove disrupted membranes.

form lysosome suspension could be obtained from $50 \mathrm{ml}$ of venous blood. The lysosomes, isolated and maintained at $2^{\circ} \mathrm{C}$ until use, were stable without release of their enzyme contents for periods in excess of $48 \mathrm{~h}$. All experiments presented were performed on organelles within $16 \mathrm{~h}$ of isolation.

Lysosome stress procedurc. The intact lysosome suspension, $0.6 \mathrm{ml}$, was mixed with $6 \mu 1$ of either the steroid to be tested solubilized in dimethyl sulfoxide (DMSO) or with DMSO alone. The final concentration of DMSO was $1 \%$ in all tubes. After mixing, the lysosome suspensions were allowed to stand for $20 \mathrm{~min}$ at room temp and then were incubated for $90 \mathrm{~min}$ at $37^{\circ} \mathrm{C}$ with gentle mixing. After incubation, intact lysosomes were removed by centrifugation at $25,000 \mathrm{~g}$ for $10 \mathrm{~min}$ and the clear supernates were assayed for enzyme activities. In some experiments the centrifuged intact lysosomes were resuspended to original volume in $0.3 \mathrm{M}$ sucrose, frozen and thawed seven times to disrupt remaining intact organelles and to release their soluble contents, and centrifuged $25,000 \mathrm{~g}$ for $10 \mathrm{~min}$. The resulting supernates were assayed for enzyme activities. In some studies, lysosomes were suspended in $0.15 \mathrm{M}$ phosphate-buffered saline, $\mathrm{pH} 7.4$, and in other studies in $0.3 \mathrm{M}$ sucrose. Identical results were obtained with each medium.

A second lysosome stress procedure was employed in some experiments. PMN leukocyte lysosomes suspended in $0.3 \mathrm{M}$ sucrose containing $30 \mathrm{U}$ aqueous heparin $/ \mathrm{ml}$ were mixed with solubilized steroid or with solvent alone at room temp. The absorbance $520 \mathrm{~nm}$ of the suspension of intact lysosomes was stable until the addition of Triton X-100 (Rohm and Haas Co., Philadelphia, Pa.). This nonionic detergent disrupts organelle membranes, releasing their soluble contents, resulting in a rapid decrease in absorbance of the lysosomal suspension (8). Volumes used were 0.8 $\mathrm{ml}$ of lysosome suspension $\left(A_{520 \mathrm{~nm}}=0.6\right)$ and $0.1 \mathrm{ml}$ steroid followed by $0.1 \mathrm{ml}$ detergent, final concentration $0.01 \%$ (vol/vol). Absorbance was measured before the addition of detergent and at intervals of $60 \mathrm{~s}$ after its addition with rapid mixing.

To study the effect of in vivo adrenocorticosteroids, normal adult males received prednisolone by mouth, $60 \mathrm{mg} /$ day in divided doses. After 3 days, venous blood PMN leukocyte lysosomes isolated from three steroid-treated individuals were pooled and stressed with heat incubation, and the liberated enzyme activity was quantitated as a percent of total enzyme content of the suspension. The results were contrasted with a lysosome suspension obtained from untreated controls. Six control subjects were needed to provide sufficient numbers of PMN leukocytes for these stress experiments. The absorbance of the organelle suspensions from both treated and control subjects was made identical before testing. In addition, sera obtained daily for $\mathbf{3}$ days before and during steroid administration were studied for their effects on detergent-stressed normal lysosomes. 0.1 $\mathrm{ml}$ of serum was mixed with $0.8 \mathrm{ml}$ of the intact lysosome suspension before the addition of $0.1 \mathrm{ml}$ of $0.1 \%$ Triton $\mathrm{X}-100$ and the absorbance change measured. This method for the detection of serum membrane reactants that modify organelle permeability has been previously described (910). A lysosomal stabilizer in the serum will retard the rate of absorbance change followed addition of the membranolytic detergent.

Activity of the lysosomal enzyme, $\beta$-glucuronidase, was measured by the method of Fishman, Springer, and Brunetti (11) with phenolphthalein glucuronide as substrate. The time of $37^{\circ} \mathrm{C}$ incubation of $0.2-\mathrm{ml}$ samples at $\mathrm{pH} 4.5$ was $6 \mathrm{~h}$. Absorbance $550 \mathrm{~nm}$ was determined after addition of glycine buffer, $\mathrm{pH}$ 10.4. Activity as determined by using a beef liver $\beta$-glucuronidase standard (Nutritional Biochemicals Corporation, Cleveland, Ohio) showed one Fishman $\mathrm{U}=0.0025 \mathrm{OD}_{550 \mathrm{~nm}} / \mathrm{h}$ at $37^{\circ} \mathrm{C}$. Acid phosphatase was determined by the method of Andersch and Szczpinski using $p$-nitrophenylphosphate as substrate (12). The time 
of incubation at $37^{\circ} \mathrm{C}, \mathrm{pH} 4.8$, of $0.2-\mathrm{ml}$ samples was $5 \mathrm{~h}$. Absorbance $420 \mathrm{~nm}$ was measured after addition of $0.1 \mathrm{~N}$ $\mathrm{NaOH} .1 \mathrm{U}$ of enzyme activity as standardized against wheat germ acid phosphatase (Sigma Chemical Co., St. Louis, Mo.) was $0.340 \mathrm{OD}_{420 \mathrm{~nm}} / 30 \mathrm{~min}$ at $37^{\circ} \mathrm{C}$.

Steroid hormones studied were 4-pregnene-11 $\beta, 17 \alpha, 21$-triol3,20-dione (hydrocortisone) and 1,4-pregnadiene-17 $\alpha, 21$-diol3,11,20-trione (prednisone) from Sigma Chemical Co., hydrocortisone sodium succinate from Upjohn Co., Kalamazoo, Mich., 9 $\alpha$-fluoro-16 $\alpha$-methylprednisolone (dexamethasone) from Merck \& Co., Inc., Rahway, N. J., and hydrocortisone acetate, hydrocortisone hemisuccinate, 4-androstene-3,17-dione (androstenedione), and $\Delta 4$-pregnene-3,20-dione (progesterone) from Mann Research Labs Inc., New York. After solubilization in DMSO, all steroids were diluted in lysosomal buffers for use in lysosome stress tests. All compounds were studied at multiple dilutions for possible inhibitory effects on lysosome enzyme activities.

\section{RESULTS}

Incubation at $37^{\circ} \mathrm{C}$ exerts a significant and reproducible stress on intact isolated human leukocyte lysosomes (Table I). In the absence of steroid hormones, incubation for $90 \mathrm{~min}$ induced a release of $20 \%$ of the total $\beta$-glucuronidase and $19 \%$ of the total acid phosphatase contents of the lysosome suspension. Total content was determined by summing the activities present in the $0.3 \mathrm{M}$ sucrose suspension after incubation and the enzyme content released by subsequent freezing and thawing of the remaining intact lysosomes. Cellular acid phosphatase from other than lysosomal sites was believed to account for the differences observed between the two enzymes assayed (13). Because $\beta$-glucuronidase is more localized to the large granule (lysosomal) fraction of PMN leukocytes (14), this enzyme was considered the

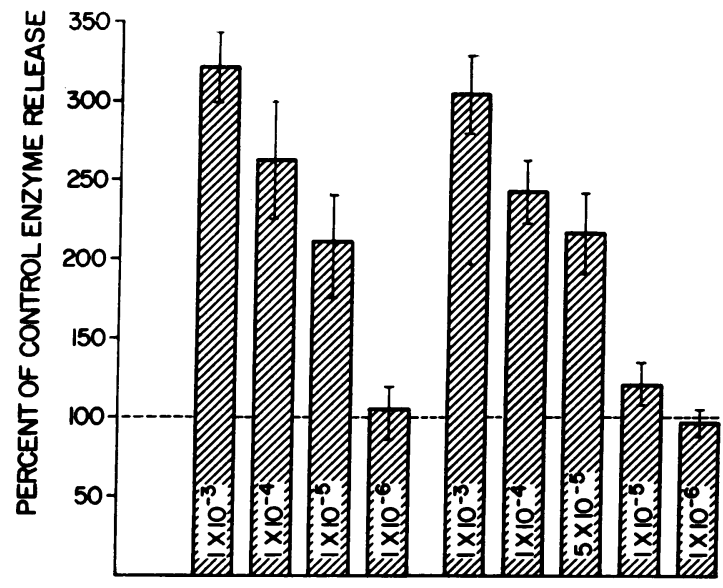

PROGESTERONE ANDROSTENEDIONE

Figure 1 Effect of steroids on $\beta$-glucuronidase release from human PMN leukocyte lysosomes. Intact lysosomes were incubated at $37^{\circ} \mathrm{C}$ for $90 \mathrm{~min}$ in varying molar concentrations of steroid solubilized in DMSO. Enzyme activities liberated from lysosomes in DMSO alone served as controls, were corrected for $\beta$-glucuronidase activity in supernates of lysosomes kept at $2^{\circ} \mathrm{C}$, and set as $100 \%$ release. Shown are means \pm 1 SD of four experiments, each with two to six replicates.

most important marker in subsequent studies on lysosome membrane permeability. Some experiments were performed with $0.15 \mathrm{M}$ phosphate-saline buffer, $\mathrm{pH} 7.4$, rather than sucrose as the suspending medium. Results obtained were within the same ranges as those seen in sucrose and data were combined.

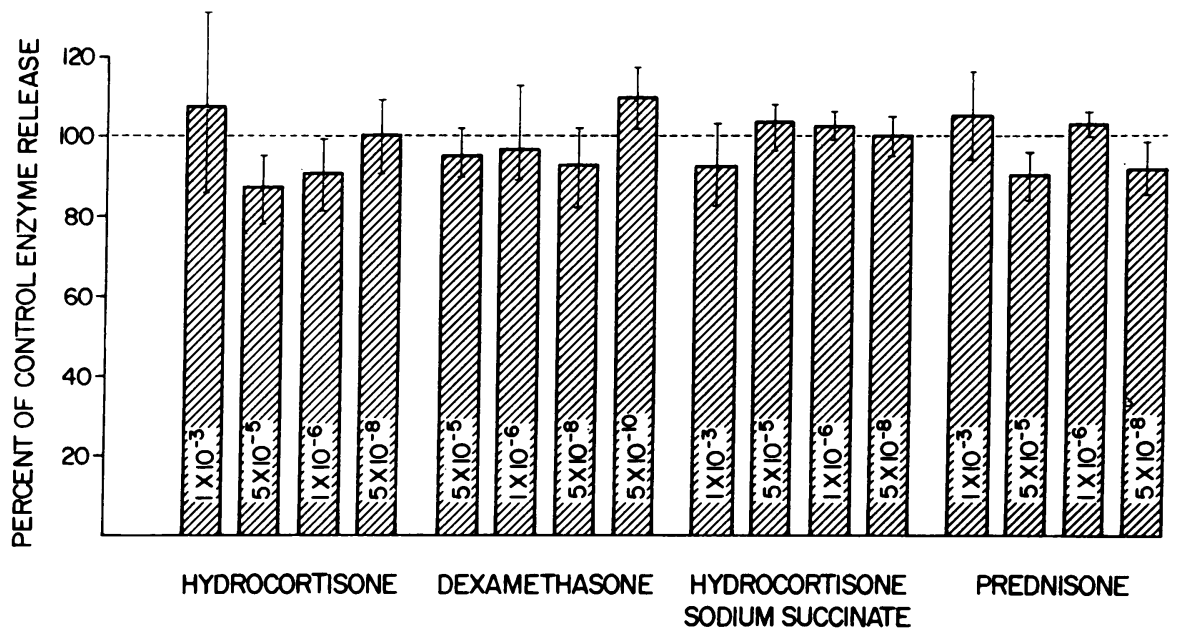

FIGURE 2 Effect of anti-inflammatory steroids on $\beta$-glucuronidase release from human PMN leukocyte lysosomes. Intact lysosomes were incubated at $37^{\circ} \mathrm{C}$ for $90 \mathrm{~min}$ in varying molar concentrations of steroid solubilized in DMSO. Enzyme activity liberated from lysosomes in DMSO alone served as a control and represented $100 \%$ release. Shown are means \pm 1 SD of four experiments, each with four replicates for all steroids except prednisone, which was studied three times, each with four replicates. 


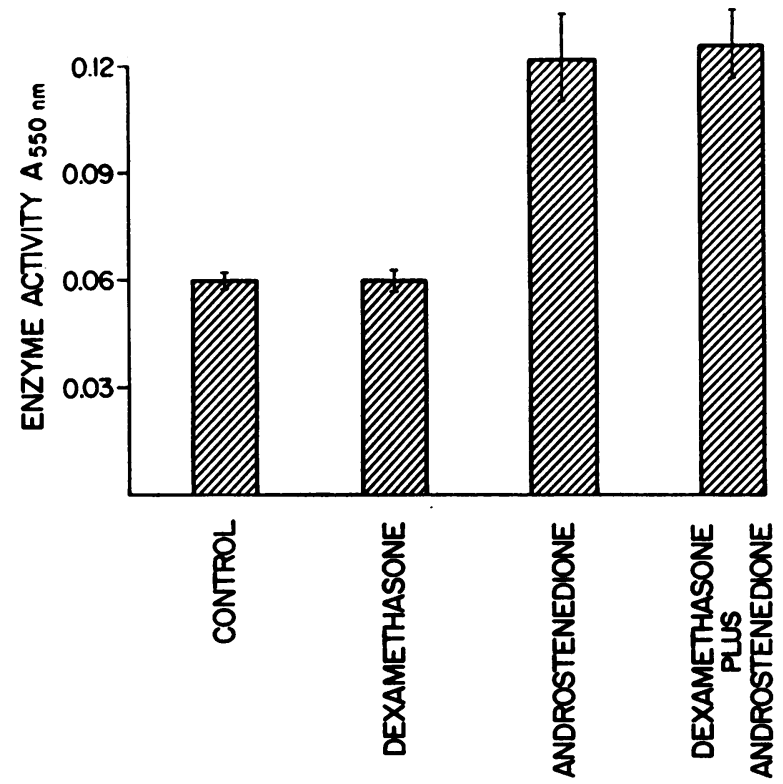

FIgURE 3 Effect of preincubation with $5 \times 10^{-6} \mathrm{M}$ dexamethasone on labilizing activity of $5 \times 10^{-6} \mathrm{M}$ androstenedione. $\beta$-Glucuronidase released from lysosomes incubated at $37^{\circ} \mathrm{C}$ for $90 \mathrm{~min}$ was corrected for enzyme activity measured in supernates of organelle suspensions maintained at $2^{\circ} \mathrm{C}$. After centrifugation, $0.2-\mathrm{ml}$ samples were incubated with phenolphthalein glucuronide and change in absorbance $550 \mathrm{~nm}$ was determined. See text for details. Shown are means \pm 1 SD of two experiments, each with three replicates.

The effects of progesterone and of androstenedione, $10^{-8}-10^{-6} \mathrm{M}$, are shown in Fig. 1. These steroids, neither oxygenated nor hydroxylated at the $\mathrm{C}-11$ position, have previously been shown to induce membrane rupture and allow leakage of enzymes from liver lysosomes (15). It can be seen that these steroids also labilize lysosomes from human PMN leukocytes. Almost the total lysosome content of $\boldsymbol{\beta}$-glucuronidase was released after incubation with $10^{-8} \mathrm{M}$ progesterone. The membranolytic effect was dose related both for progesterone and androstenedione. Neither steroid inhibited the enzyme measured.

The anti-inflammatory steroids previously shown to stabilize liver organelles, however, were not capable of retarding release of enzyme from PMN lysosomes (Fig. 2). Hydrocortisone, dexamethasone, prednisone, and hydrocortisone sodium succinate did not prevent the release of $\boldsymbol{\beta}$-glucuronidase from lysosomes stressed by heat incubation. These steroids were studied at various concentrations including the usual physiologic and pharmacologic ranges. Less of the lysosomal enzyme assayed was found in the supernate after incubation of the organelles with either hydrocortisone hemisuccinate or with hydrocortisone acetate, in concentrations ranging from $10^{-8}$ to $10^{-6} \mathrm{M}$. The activities of both of the soluble granulocyte lysosomal enzymes studied were inhibited by the addition of these two compounds, this effect being dose related. Thus, the finding of less enzyme in the supernate was due to enzyme inhibition by these corticosteroid preparations rather than to lysosomal membrane stabilization. In no case could any of the anti-inflammatory steroids studied be found to stabilize PMN leukocyte lysosomes to a statistically significant degree.

Lysosomes preincubated for $20 \mathrm{~min}$ at $23^{\circ} \mathrm{C}$ with dexamethasone, $5 \times 10^{-5} \mathrm{M}$, were then challenged with the labilizer, androstenedione, $5 \times 10^{-6} \mathrm{M}$ (Fig. 3). After $37^{\circ} \mathrm{C}$ incubation for $90 \mathrm{~min}$, lysosomes released as much enzyme as when incubated in androstenedione alone. $\beta$-Glucuronidase release in dexamethasone alone did not differ from the control.

PMN leukocyte lysosomal membrane stabilization by an anti-inflammatory steroid was also investigated by a different stress technique (Fig. 4). Hydrocortisone hemisuccinate at either $5 \times 10^{-3}$ or $5 \times 10^{-4} \mathrm{M}$ could not protect isolated organelles from the lytic effects of a nonionic detergent. A stabilizing agent would be expected to retard the change in absorbance of the lysosomal suspension after the addition of the membranolytic Triton X-100. In no case was the $A s s 0 \mathrm{~nm}$ change of the steroid-treated lysosomes statistically different from controls.

Studies with an anti-inflammatory steroid (dexamethasone) and with a membrane labilizer (progesterone)

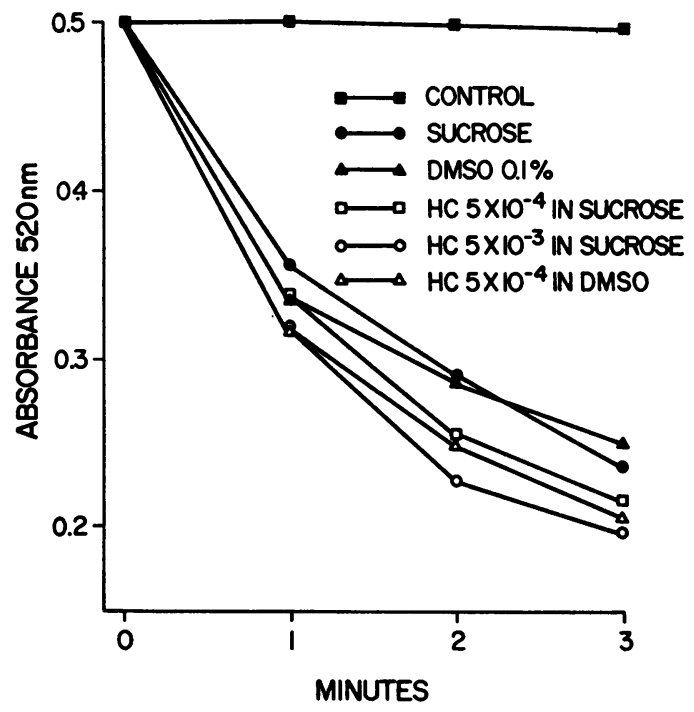

Figure 4 Effect of hydrocortisone hemisuccinate (HC) on lysis of PMN leukocyte lysosomes by Triton X-100 $(0.01 \%)$. Steroid was solubilized either in ethanol and diluted in $0.3 \mathrm{M}$ sucrose or in $1 \% \mathrm{DMSO}$, and preincubated with intact organelles, and change in absorbance $520 \mathrm{~nm}$ was measured after addition of nonionic detergent. Solvents without $\mathrm{HC}$ were also studied. Control shows $A_{520 \mathrm{~nm}}$ change without Triton X-100. Presented are the means of 8-12 replicates for each point. 
were performed with normal rat liver as the lysosome source (Fig. 5). Liver organelles contained in the subcellular fraction sedimenting between $1,000 \mathrm{~g}$ for $10 \mathrm{~min}$ and $25,000 \mathrm{~g}$ for $10 \mathrm{~min}$ were stressed with $37^{\circ} \mathrm{C}$ incubation for $45 \mathrm{~min}(16)$. This incubation period caused the liver organelles to leak $16.5 \pm 1.5 \%$ of their total enzyme content in the absence of steroid. Enzyme release was augmented by the PMN leukocyte lysosome labilizer, progesterone, at several concentrations. Unlike its action on PMN leukocyte lysosomes, however, dexamethasone prevented the release of $\beta$-glucuronidase from heatstressed liver organelles. Significantly less enzyme was detected at both $5 \times 10^{-5}$ and $1 \times 10^{-6} \mathrm{M}$ concentrations, and dexamethasone did not inhibit the liver lysosomal enzyme studied.

Lysosomes isolated from normal human volunteers receiving prednisolone were stressed by heat incubation and the $\boldsymbol{\beta}$-glucuronidase activity released was assayed. A simultaneously studied organelle suspension obtained from control subjects released $38.8 \pm 1.9 \%$ (SEM) of the total granule content of $\beta$-glucuronidase after incubation at $37^{\circ} \mathrm{C}$ for $90 \mathrm{~min}$. The lysosomes from steroidtreated volunteers released $37.9 \pm 2.9 \%$. These values represent data obtained from five control and six steroid studies, each with three replicates. The plasma cortisol concentrations studied at the time PMN leukocytes were obtained averaged $14.7 \mu \mathrm{g} / 100 \mathrm{ml}$ in control subjects and $0.8 \mu \mathrm{g} / 100 \mathrm{ml}$ in volunteers receiving prednisolone. Thus in vivo anti-inflammatory steroids did not render

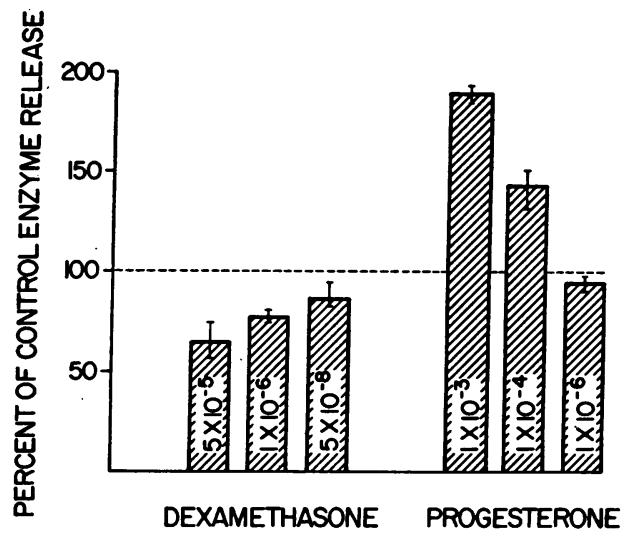

Figure 5 Steroid effects on $\beta$-glucuronidase release from rat liver lysosomes. Liver organelles in $0.25 \mathrm{M}$ sucrose-0.02 $\mathrm{M}$ Tris, $\mathrm{pH} 7.1,\left(A_{\mathrm{sen} \mathrm{nm}}\right.$ of $1: 10$ dilution $\left.=1.000\right)$ were preincubated for $20 \mathrm{~min}$ at $2^{\circ} \mathrm{C}$ with steroid hormone or its solvent and then heat-stressed at $37^{\circ} \mathrm{C}$ for $45 \mathrm{~min}$. Enzyme liberated in solvent alone was set as $100 \%$ release. Shown are means $\pm 1 \mathrm{SD}$ of six determinations. $P$ values (Student's $t$ test) versus the control for $5 \times 10^{-5}$ and $1 \times 10^{-6}$ dexamethasone and for $1 \times 10^{-6} \mathrm{M}$ progesterone are $<0.02$, and for $1 \times 10^{-8} \mathrm{M}$ progesterone $<0.01$. Differences observed at the other steroid concentrations were not significant.

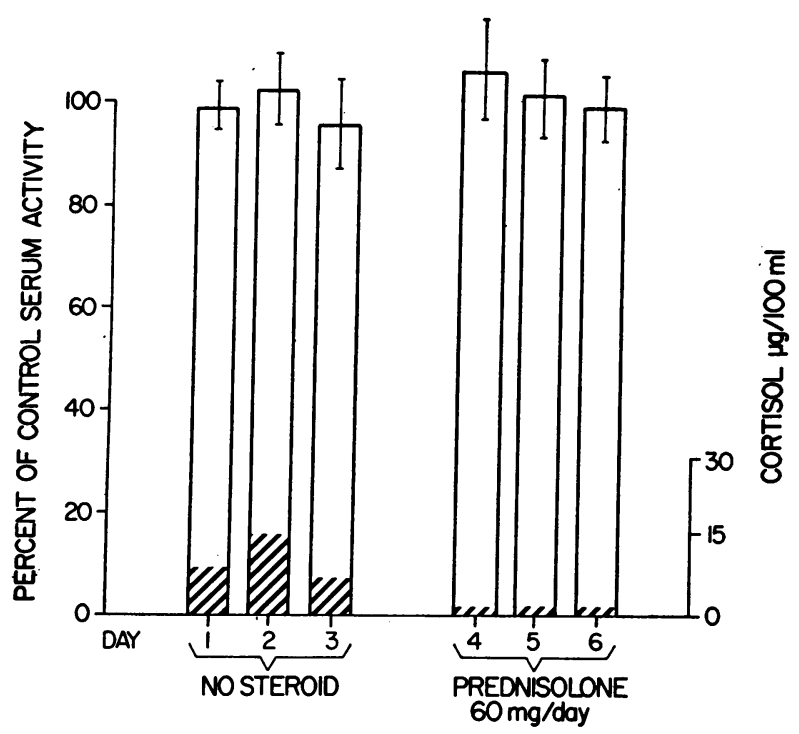

FIGURE 6 Effect of in vivo prednisolone on isolated lysosomes. Sera obtained daily before and during prednisolone administration were mixed (final concentration $1: 10$ ) with intact organelles before the addition of Triton X-100. Absorbance $520 \mathrm{~nm}$ change in control sera was set at $100 \%$ activity. Shown are means and ranges of six experiments, each with 4-8 replicates. Shaded areas depict 8 A.M. plasma cortisol concentrations.

PMN leukocyte lysosomes more resistant to heat stress. Furthermore, serum obtained during prednisolone treatment did not protect isolated organelles from lysis by Triton X-100 (Fig. 6). Sera obtained from subjects receiving adrenocorticosteroid had the same effect as control sera. The membranolytic action of the detergent was not impeded. As anticipated, plasma cortisol concentrations were depressed by the exogenous prednisolone, indicating that the volunteers had ingested the steroid.

\section{DISCUSSION}

The methods used in these experiments are the techniques commonly employed to study the effects of steroid hormones on lysosomal membranes $(1,2,8,15,16)$. Two standard stress procedures were studied: heat incubation and detergent lysis, both known to induce a predictable leakage of hydrolases from intact lysosomes. Using these methods with liver organelles, we could reproduce the observations previously published on the labilizing and stabilizing effects of certain hormones. However, substituting lysosomes derived from the cell most concerned with acute inflammatory reactions, the PMN leukocyte, we could not demonstrate membrane stabilization by anti-inflammatory corticosteroids. Direct membrane interaction was clearly evident in the case of progesterone and androstenedione, two compounds known to 
induce leakage of liver organelle membranes (15). But the anti-inflammatory steroid hormones we tested exerted no stabilizing activity on PMN leukocyte lysosomes. And the agents were studied at various concentrations including both physiologic and pharmacologic ranges. With only two steroids, hydrocortisone hemisuccinate and hydrocortisone acetate, could we find less enzyme activity in the supernates after stressing lysosomes by heat incubation. But in both cases this was due to enzyme inhibition by these hormone preparations rather than to lysosomal membrane stabilization. de Duve et al. (1) observed less free acid phosphatase activity released from liver organelles in cortisone acetate and cautioned about the possible misinterpretation of lysosome membrane stabilization by what in fact were enzyme inhibitors. And finally, the administration of prednisolone to human volunteers not only failed to modify the integrity of their PMN leukocyte lysosomes, but also did not impart a stabilizing activity to their sera when tested with normal leukocyte granules.

Numerous publications have dealt with the effects of corticosteroids on liver lysosomal membrane integrity. Not all studies $(17,18)$ have confirmed the stabilization hypothesis. Either no effect or mild stabilization has been noted with anti-inflammatory steroids, depending upon experimental conditions. These diverse observations have also been found using PMN leukocyte lysosomes. Thus, Weissmann, Becher, and Thomas (8) showed that $10^{-3}$ $M$ hydrocortisone would not protect rabbit peritoneal PMN leukocyte lysosomes from streptolysin $O$ lysis. And Willis, Davison, Ramwell, Brocklehurst, and Smith (19) could not alter the release of $\beta$-glucuronidase from isolated lysosomes by hydrocortisone even at concentrations up to $1 \mathrm{mg} / \mathrm{ml}$. Both hydrocortisone and paramethasone were found to be without effect at $10^{-8}-10^{-6} \mathrm{M}$ on rat blood leukocyte lysosomes but capable of stabilizing rabbit and guinea pig peritoneal exudate PMN organelles using hypotonic incubation media $(20,21)$. The variables found by these authors to alter lysosomal membrane permeability have included species and organ sources of organelles, tonicity and $\mathrm{pH}$ of media, and the types of stress procedures employed. In addition, lysosomes from both liver (22) and PMN leukocytes $(23,24)$ are heterogeneous in composition and form. These variables could account for some of the published discrepancies on how drugs affect membrane stability. We used experimental conditions more physiologic for our studies with lysosomes. Whereas both liver and PMN leukocyte lysosomes can be labilized by progesterone and androstenedione, only liver organelles were stabilized by the anti-inflammatory steroids, and then to only a mild degree.

The reasons for the different reactivity of liver and PMN leukocyte lysosomes to anti-inflammatory corti- costeroids are unclear; our observations could be due to variations in membrane structure. Although the studies performed thus far $(25,26)$ are in agreement concerning protein content (both liver and leukocyte organelle membranes containing approximately $50 \%$ protein/wet wt) differences have been found in the lipids of these membranes. Rat liver lysosomal membranes contained cholesterol and phospholipid at a ratio of $1: 3.4$ (25), and a cell membrane fraction from rabbit PMN leukocyte granules had a ratio of $1: 1.4$ (26). If steroids alter permeability by their action at the lipid-water interface of membranes, these differences in the composition of the membrane lipids could explain our results.

Using viable cell preparations, numerous authors, including Mandell, Rubin, and Hook (5) and Wiener et al. (6), have shown that hydrocortisone prevents the release of lysosomal hydrolases during phagocytosis. This association with anti-inflammatory corticosteroids has also been observed with in vivo models of inflammation $(27,28)$ and lysosome rupture (29). But direct membrane interaction by these compounds and resulting stabilization need not be invoked to explain their antiphlogistic actions. Corticosteroids have a wide range of biological activities that could account for their suppressive effects on inflammation (30-34). Interference with glucose transport (33) and inhibition of ATP generation (34), or suppression of $\mathrm{NADH}$ oxidase activity (5) are several actions that could lead to depressed cell function. After phagocytosis, these effects of hydrocortisone would prevent the intracellular metabolic activity necessary for merger of organelle membranes with the endocytic vacuole, the subsequent degranulation, and the extrusion of lysosome contents from the cell. In light of our experimental observations presented above, these are more plausible explanations for the mechanism of anti-inflammatory steroid action than the hypothesis of direct membrane stabilization.

\section{ACKNOWLEDGMENTS}

Sharon E. Vance and June K. Rushing provided expert technical assistance.

This study was supported in part by grants from The Robert A. Welch Foundation, Houston, Tex., and The South Central Texas Chapter of the Arthritis Foundation.

\section{REFERENCES}

1. de Duve, C., R. Wattiaux, and M. Wibo. 1962. Effects of fat-soluble compounds on lysosomes in vitro. Biochem. Pharmacol. 9: 97-116.

2. Weissmann, G., and L. Thomas. 1963. Studies on lysosomes: II. The effect of cortisone on the release of acid hydrolases from a large granule fraction of rabbit liver induced by an excess of vitamin A. J. Clin. Invest. 42: 661-669.

3. Weissmann, G. 1967. The role of lysosomes in inflammation and disease. Annu. Rev. Med. 18: 97-112. 
4. Wright, D. G., and S. E. Malawista. 1973. Mobilization and extracellular release of granular enzymes from human leukocytes during phagocytosis: inhibition by colchicine and cortisol but not by salicylate. Arthritis Rheum. 16: 749-758.

5. Mandell, G. L., W. Rubin, and E. W. Hook. 1970. The effect of an NADH oxidase inhibitor (hydrocortisone) on polymorphonuclear leukocyte bacterial activity. J. Clin. Invest. 49: 1381-1388.

6. Wiener, E., Y. Marmary, and Z. Curelaru. 1972. The in vitro effect of hydrocortisone on the uptake and intracellular digestion of particulate matter by macrophages in culture. Lab. Invest. 26: 220-226.

7. Chodirker, W. B., G. N. Bock, and J. H. Vaughan. 1968. Isolation of human PMN leukocytes and granules: observations on early blood dilution and on heparin. J. Lab. Clin. Med. 71: 9-19.

8. Weissmann, G., B. Becher, and L. Thomas. 1964. Studies on lysosomes. V. The effects of streptolysins and other hemolytic agents on isolated leucocyte granules. J. Cell Biol. 22 : 115-126.

9. Persellin, R. H. 1969. Lysosome stabilization by leukocyte granule membrane antiserum. J. Inmmunol. 103: 3944.

10. Hempel, K. H., L. A. Fernandez, and R. H. Persellin. 1970. Effect of pregnancy sera on isolated lysosomes. Nature (Lond.). 225: 955-956.

11. Fishman, W. H., B. Springer, and R. Brunetti. 1948. Application of an improved glucuronidase assay method to the study of human blood $\beta$-glucuronidase. J. Biol. Chem. 173: 449-456.

12. Andersch, M. A., and A. J. Szczypinski. 1947. Use of p-nitrophenylphosphate as the substrate in determination of serum acid phosphatase. Am. J. Clin. Pathol. 17: 571-574.

13. Farquhar, M. G., D. F. Bainton, M. Baggiolini, and C. de Duve. 1972. Cytochemical localization of acid phosphatase activity in granule fractions from rabbit polymorphonuclear leukocytes. J. Cell Biol. 54: 141-156.

14. Weissmann, G., R. B. Zurier, and S. Hoffstein. 1972. Leukocytic proteases and the immunologic release of lysosomal enzymes. Am. J. Pathol. 68: 539-559.

15. Weissmann, G. 1965. Studies of lysosomes-VI. The effect of neutral steroids and bile acids on lysosomes in vitro. Biochem. Pharmacol. 14: 525-535.

16. Persellin, R. H. 1972. Lysosome stabilization by adjuvant arthritis serum. Arthritis Rheum. 15: 144-152.

17. Ignarro, L. J. 1971. Effects of anti-inflammatory drugs on the stability of rat liver lysosomes in vitro. Biochem. Pharmacol. 20: 2847-2860.

18. Brown, J. H., and N. L. Schwartz. 1969. Interaction of lysosomes and anti-inflammatory drugs (33938). Proc. Soc. Exp. Biol. Med. 131: 614-620.

19. Willis, A. L., P. Davison, P. W. Ramwell, W. E. Brocklehurst, and B. Smith. 1972. Release and actions of prostaglandins in inflammation and fever: inhibition by anti-inflammatory and and antipyretic drugs. In Prostaglandins in Cellular Biology. P. W. Ramwell and
B. B. Pharriss, editors. Plenum Publishing Corporation, New York. 227-268.

20. Ignarro, L. J. 1971. Dissimilar effects of anti-inflammatory drugs on stability of lysosomes from peritoneal and circulating leukocytes and liver. Biochem. Pharmacol. 20 : 2861-2870.

21. Ignarro, L. J., and C. Colombo. 1972. Enzyme release from guinea-pig polymorphonuclear leucocyte lysosomes inhibited in vitro by anti-inflammatory drugs. Nat. Ncw Biol. 239: 155-157.

22. Tanaka, K., and Y. Iizuka. 1968. Suppression of enzyme release from isolated rat liver lysosomes by non-steroidal anti-inflammatory drugs. Biochem. Pharmacol. 17: 20232032.

23. Baggiolini, M., J. G. Hirsch, and C. de Duve. 1969. Resolution of granules from rabbit heterophil leukocytes into distinct populations by zonal sedimentation. $J$. Cell Biol. 40: 529-541.

24. Welsh, I. R. H., and J. K. Spitznagel. 1971. Distribution of lysosomal enzymes, cationic proteins, and bactericidal substances in subcellular fractions of human polymorphonuclear leukocytes. Infect. Immun. 4: 97-102.

25. Thines-Sempoux, D. 1967. Chemical similarities between the lysosome and plasma membranes. Biochem. $J$. $105: 20-21 P$

26. Woodin, A. M., and A. A. Wieneke. 1966. Composition and properties of a cell-membrane fraction from the polymorphonuclear leukocyte. Biochem. J. 99: 493-500.

27. Arrigoni-Martelli, E., and A. Restelli. 1972. Release of lysosomal enzymes in experimental inflammations: effects of anti-inflammatory drugs. Eur. J. Pharmacol. 19: 191-198.

28. Andersen, A. J. 1970. Lysosomal enzyme activity in rats with adjuvant-induced arthritis. Ann. Rheum. Dis. 29: 307-313.

29. Szego, C. M. 1972. Lysosomal membrane stabilization and antiestrogen action in specific hormonal target cells. Gynecol. Invest. 3 : 63-95.

30. Weissmann, G., and L. Thomas. 1964. The effects of corticosteroids upon connective tissue and lysosomes. Recent Prog. Horm. Res. 20 : 215-245.

31. Cline, M. J., and K. L. Melmon. 1966. Plasma kinins and cortisol: a possible explanation of the anti-inflammatory action of cortisol. Science (Wash. D. C.). 153: $1135-1137$.

32. Cooper, M. R., L. R. DeChatelet, and C. E. McCall. 1972. The in vitro effect of steroids on polymorphonuclear leukocyte metabolism (36916). Proc. Soc. Exp. Biol. Med. 141: 986-990.

33. Gemsa, D., C. H. Woo, H. H. Fudenberg, and R. Schmid. 1973. Erythrocyte catabolism by macrophages in vitro. The effect of hydrocortisone on erythrophagocytosis and on the induction of heme oxygenase. $J$. Clin. Invest. 52: 812-822.

34. Young, D. A. 1969. Glucocorticoid action on rat thymus cells: interrelationships between carbohydrate protein, and adenine nucleotide metabolism and cortisol effects on these functions in vitro. J. Biol. Chem. 244: 22102217. 